Canad. Math. Bull. Vol. 23 (4), 1980

\title{
A NON-NORMAL FUNCTION WHOSE DERIVATIVE IS OF HARDY CLASS $H^{p}, 0<p<1$
}

\author{
BY \\ SHINJI YAMASHITA
}

Let $H^{p}(0<p \leq \infty)$ be the Hardy class of functions holomorphic in $D=$ $\{|z|<1\}$, and let $f$ be a function holomorphic in $D$. It follows from the well known theorem [1, Theorem 3.11, p. 42] that if (I) $f^{\prime} \in H^{1}$, then (II) $f$ can be extended continuously to the closed disk $\{|z| \leq 1\}$, and consequently, (III) $f$ is normal in $D$ in the sense of O. Lehto and K. I. Virtanen [2]. Since there is a considerable gap between (II) and (III), one would suspect that the condition (I) might be much stronger than necessary to obtain the conclusion (III). However, it is curious that the implication (I) $\Rightarrow$ (III) is sharp as the following theorem shows.

THEOREM. There exists a non-normal holomorphic function $f$ in $D$ such that $f^{\prime} \in \bigcap_{0<p<1} H^{p}$.

Let $\left\{z_{n}\right\}$ be a sequence in $D$ such that

$$
1-\left|z_{n+1}\right| \leq c\left(1-\left|z_{n}\right|\right)<c, \quad n=1,2, \ldots,
$$

where $0<c<1$ is a constant. Assume that there exists a subsequence $\left\{z_{n_{\mathrm{j}}}\right\}$ of $\left\{z_{n}\right\}$, converging to 1 . We may consider the Blaschke product

$$
B(z)=\prod_{n=1}^{\infty} \frac{\left|z_{n}\right|}{z_{n}} \frac{z_{n}-z}{1-\bar{z}_{n} z}
$$

because $\sum\left(1-\left|z_{n}\right|\right) \leq\left(1-\left|z_{1}\right|\right) \sum c^{n-1}<\infty$.

The function we wish to examine is the product $f=B g$, where $g(z)=$ $-\log (1-z), g(0)=0$.

It follows from the known estimate $[1, \mathrm{p} .156]$ that

$$
\left(1-\left|z_{n}\right|^{2}\right)\left|B^{\prime}\left(z_{n}\right)\right|=\prod_{\substack{k=1 \\ k \neq n}}^{\infty}\left|\frac{z_{n}-z_{k}}{1-\bar{z}_{k} z_{n}}\right| \geq \prod_{k=1}^{\infty}\left(\frac{1-c^{k}}{1+c^{k}}\right)^{2}=a>0
$$

for $n=1,2, \ldots$ Therefore,

$$
\left(1-\left|z_{n_{j}}\right|^{2}\right)\left|f^{\prime}\left(z_{n_{j}}\right)\right| /\left(1+\left|f\left(z_{n_{j}}\right)\right|^{2}\right)=\left(1-\left|z_{n_{j}}\right|^{2}\right)\left|B^{\prime}\left(z_{n_{j}}\right) g\left(z_{n_{j}}\right)\right| \geq a\left|g\left(z_{n_{j}}\right)\right| \rightarrow \infty
$$

as $j \rightarrow \infty$, which proves that $f$ is not normal in $D$.

Received by the editors February 27, 1979 and in revised form May 22, 1979. 
Now, for each $0<p<1$,

$$
\left|f^{\prime}\right|^{p} \leq\left|B^{\prime} g\right|^{p}+\left|g^{\prime}\right|^{p} .
$$

Since $g^{\prime} \in \bigcap_{0<p<1} H^{p}$, we have only to show that

$$
B^{\prime} g \in H^{p} \quad \text { for each } 0<\mathrm{p}<1 .
$$

First of all, since $\sum\left(1-\left|z_{n}\right|\right)^{1-q}<\infty$ for $\frac{1}{2}<q<1$ by (1), it follows from [3, Theorem 2] that $B^{\prime} \in H^{q}$. Therefore,

$$
B^{\prime} \in \bigcap_{0<q<1} H^{q}
$$

Now, for the proof of (2), we choose $1<\lambda<1 / p$, and then $\mu$ such that $\lambda^{-1}+\mu^{-1}=1$. It then follows from the Hölder inequality that, for each $0<r<$ 1 ,

$$
\int_{0}^{2 \pi}\left|B^{\prime}\left(r e^{i \theta}\right) g\left(r e^{i \theta}\right)\right|^{p} d \theta \leq\left[\int_{0}^{2 \pi}\left|B^{\prime}\left(r e^{i \theta}\right)\right|^{p \lambda} d \theta\right]^{1 / \lambda}\left[\int_{0}^{2 \pi}\left|g\left(r e^{i \theta}\right)\right|^{p \mu} d \theta\right]^{1 / \mu} .
$$

The assertion (2) now follows on combining (3) and $g \in \bigcap_{0<q<\infty} H^{q}$.

\section{REFERENCES}

1. Peter L. Duren, Theory of $H^{p}$ spaces. Academic Press, New York and London, 1970.

2. Olli Lehto and Kaarlo I. Virtanen, Boundary behaviour and normal meromorphic functions. Acta Math. 97 (1957), 47-65.

3. David Protas, Blaschke products with derivative in $H^{p}$ and $B^{p}$. Michigan Math. J. 20 (1973). 393-396.

DEPARTMENT OF MATHEMATICS

TOKYO METROPOLITAN UNIVERSITY

Fukazawa, Setagaya-Ku

TOKYO, 158 JAPAN 